\title{
Cytochemical changes of the proximal convolution of the kidney in mouse after injection of alloxan
}

\author{
Taka Kashimura \\ Department of Anatomy, School of Medicine, Keio-Gijuku \\ University, Shinjuku-ku, Tokyo \\ (Director: Prof. T. Taniguchi)
}

\section{Introduction}

In 1937, J a c o b s found that, the rabbit died of hypoglycemia, succeeding to initial hyperglycemia after the administration of alloxan, a derivative of uric acid, and that it had been saved from death by the administration of glucose. B a i l e $y$ and B a i l e y (1943), suggested by J a cobs' experiment, expected that administration of glucose in the hypoglycemic state might make the rabbit live along with his diabetic condition and realized experimentally the occurence of hyperglycemia for a long duration. Succeeding these experiments, various experimental works on alloxan diabetes have been made and almost of them are cited in the paper of D u f $f$ (1945).

In $1950,0 \mathrm{y}$ a insisted on the important role the kidney plays in the genesis of alloxan diabetes as a result of his experiment. Also in our country, O k a m o to (1951) worked out the details in the pathologic histologic alternations of the kidney in alloxan diabetes, which were confirmed by others including $\mathrm{Nag}$ a h a m a $(1951,1952)$ and Ko s a k a et al. (1951). No report, however, has so far been made public on cytochemical alternations in the kidney influenced by alloxan.

In order to know cytochemical changes in the kidney at a relative short interval after administration of alloxan, an attempt was made to observe the magnitude of alkaline phosphatase, acid phosphatase and PAS positive substance as well as glycogen and proteins in kidney tissues.

In this article, a part of the results of the experiments, namely the alternations of these substances in proximal convolution will- be reported. 


\section{Material and Method}

55 male mice, ranging from 15 to $25 \mathrm{~g}$ in body weight, were used in this study. 25 of them were injected intraperitoneally with $0.5 \mathrm{cc}$ of water solution of alloxan. These 25 mice were devided into five groups and laparatomized under ether anesthesia respectively at half an hour, 1 hour, 2 hours, 4 hours, and 6 hours intervals after injection. A part of the kidneys obtained are fixed with alcohol and the remainder with cold aceton. Other 30 mice were used as control; 5 of them were left untreated and 25 were injected with $0.5 \mathrm{cc}$ of distilled water intraperitoneally.

Fixed preparations are all embedded in paraffin and sectioned in 5 microns.

For the demonstration of alkaline and acid phosphatase, G o m or i revised method was applied; sections were left immersed in the solution for 1 hour for the demonstration of alkaline phosphatase and for 13 hours for acid phosphatase. Polysaccharides were stained on PAS methods and glycogen was differentiated from others by diastase digestion.

Proteins were stained by $\mathrm{Hg}-\mathrm{BPB}$ method ( $\mathrm{M} \mathrm{a} \mathrm{zia}$ et al., 1953) and by alloxan-Schiff method (Y a s u ma and Ich ik a wa, 1951).

Control sections were examined not only on the same method but by Heidenhain's hematoxylin method with Zenker-formalin fixation.

Alloxan used in this study is alloxan monohydrate offered by the Wako-junyaku company.

\section{Results}

In order to describe the findings, it is thought to be convenient to devide the proximal tubule into two parts, proximal portion and distal portion, according to L o n g le y and F is cher (1954).

A) Findings on control sections stained with Heidenhain's iron hematoxylin method with Zenker-formalin fixation.

1) Proximal portions (Fig. 1):

Proximal portions arising from glomeruli are lined with short columnar and cuboidal dark cells with basement membrane and brush border. Lumen of the tubules of this portion are of various shapes irregularly round or star-like and sometimes so narrow as to be almost closed.

Epithelial cells of the proximal portion are not sharply outlined 
and their cytoplasm is turbid and unclear. The nucleus has a spheric form and its nucleic membrane stains relatively distinct. Karyoplasm is bright and contains chromatin threads or granules; 2-5 nucleoli are situated off center and less often in its center. A single line of fine granules, staining deeply with iron hematoxylin is seen adjacent to the boundary between brush border and cytoplasm. Basal striation is seen as close lines of relatively large mitochondrial threads or rodlets running parallel to the longitudinal cell axis from the bottom of a cell up to the hight of the nucleus and leaves a narrow protoplasmic zone unstriated below the brush border. Besides these mitochondrial granules, a few granules of larger size are recognized.

Some of the cells of tubules are swollen and their free surface is projected into the lumen of tubules in papillary shape. Brush border of these cells which stains homogenously gray becomes very thin or sometimes disappears. Their cytoplasm with poor basal striation seems to be clearer and has many stainable granules gathering in its cytoplasm between nucleus and free surface. It may by ascribed in part to the fixation method with Zenker-formalin that vacuolation cannot be recognized in such cells. Sunaga (1955) regarded this picture as indicated, as a secretion phase of cells of tubules. And he states moreover that swollen cells of tubules, the cytoplasm of which is projected into the lumen of tubules in hill-like shape with well defined brush border and without any stainable granules, must be in the absorption phase. Similar pictures can be observed in sect ous of the kidney of normal mice.

2) Distal portion (Fig. 2)

A distal portion exists in the medullary ray and boundary zone between medulla and cortical zone. Epithelial cells of the distal portion, like those of the proximal portion, are dark and have brush border; cell walls are indistinct. The lumen of tubules is in general wider than that of the proximal portion. Karyoplasm is enriched with chromatin and stains rather deep. Findings on basal striation markedly differ from those in cells of the proximal portion. Construction of basal striation is much weaker, that is, mitochondrial threads and rodlets are arranged in rough lines along the longitudinal cell axis. Basal striation is hardly recognized in cells at the end of the distal portion. But the number of mitochondrial granules and other stainable granules to the contrary increase so much, that they can be recognized not only in the basal part of the cytoplasm but upward to the nucleus level too. 
Also in the distal portion, the pictures indicating either the secretion or absorption phase of epithelial cells can be observed.

B) Activity of alkaline phosphatase

1) Control (fig. 3)

a) Proximal portion (fig. 4)

The brush border is extremly thick and shows strong activity. The lumen of tubules is of irregular radiant shape because of increased thickness of brush border and it is sometimes seen to be almost closed and as black lines.

Nucleus shows weak activity as a whole, but the nuclear membrane sometimes shows moderate activity. The nucleolus shows moderate activity, although it sometimes can not be differentiated from karyoplasm. Karyoplasm shows weak activity in general but it stains inhomogenously. Karyoplasm contains threads showing strong activity.

Cytoplasm in contact with the brush border shows strong activity but shows weak activity in its basal part. A part of cytoplasm forms a ring of the weakest activity arround the nucleus. Basal striation is recognized as fine threads showing moderate activity.

In cells, swollen and projected into the lumen of tubules (fig. 5), the brush border becomes thin or entirely disappears. The projected part of their cytoplasm itself shows weakest activity but contains granules showing strong activity. The lumen of such tubules contain a little amount of substance showing moderate or strong activity. The basement membrane shows partially strong and partially moderate activity.

b) Distal portion (fig. 6)

Brush border showing extremely strong activity is thinner than that in the proximal portion and hence the lumen of tubules is larger than that of the proximal portion. Nuclear membrane shows weak activity. Karyoplasm showing weakest activity contains fine threads and granules of relatively strong activity. A nucleolus shows sometimes stronger activity. The cytoplasm near the lumen in contact with brush border shows strong activity. But other parts of cytoplasm show weak activity, and little activity especially around the nucleus. Of the particle contained in cytoplasm, granules in the cytoplasm between nucleus and brush border and threads in its basal part of the cytoplasm show stronger activity than others in the same place. Basement membrane shows generally weak but sometimes strong activity.

Activity in each part of the epithelial cell of the distal portion is gradually reduced in the cells nearer to Henle's loop (fig. 7). Espe- 
cially in some parts of the brush border of cells near Henle's loop, activity is so greatly reduced that the boundary between the brush border and cytoplasm becomes unclear. But other parts of the same brush border still show strong activity and, in addition, a part of cytoplasm in contact with these parts of brush border is sometimes observed to show strong activity. Such a part of cytoplasm as shows strong activity contains granules of relatively strong activity.

2) Findings on groups injected with alloxan.

a) 30 minutes after injection; (fig. 8)

i) Proximal portion

Many of the epithelial cells show so strong an activity that they look as if they were stained homogenously black under low power. The brush border shows markedly increased activity. But a narrow zone of cytoplasm around the nucleus shows moderate activity. Karyoplasm shows moderate activity and nuclear membrane, strong activity. Such an increase in activity is marked especially in the cells of the proximal tubules near glorreruli. In the epithelium near the distal portion, the number of cells increases that show activity of the same degree with those in control.

ii) Distal portion.

A brush border showing increased activity can be observed even in the cells near Henle's loop. The number of granules showing strong activity in the cytoplasm between nucleus and its free surface or in the cytoplasm near the lumen seems to be increased.

b) 1 hour after injection; (fig. 9)

i) Proximal portion (fig. 10).

Under low power examination there can be observed so many cells showing strong activity that the proximal portion seems to be stained black as a whole. In the basal part of cytoplasm, rodlets and granules of relatively strong activity are observed besides basal striation.

In cells near the distal corsion the brush border shows an activity of the same degree with control, but both basement membranes including the basal part of cytoplasm and nuclear substance show increased activity. Many granules of greatly strong activity can be observed in the cytoplasm between nucleus and brush border and a few of them in its basal part of the cytoplasm.

ii) Distal portion (fig. 11).

Almost over the whole length of the distal portion, many cells can be found which show more increased activity than in group a). The brush borders of these cells are thinner to make the lumen of tubules 
a little larger. Some of the enlarged lumen of tubules contains network of moderate or sometimes of strong activity.

Compared with both controls and group a), cytoplasm shows increased activity, but it leaves a narrow zone of weaker activity in ring form around the nucleus.

Nucleus also shows increased activity, that is, karyoplasms show moderate activity and nuclear membrane, moderate or sometimes strong activity. In addition to these findings, rodlets unclearly outlined are observed in the basal part of the cytoplasm near the proximal portion. The basement membrane shows a little stronger activity than those of controls.

c) 2 hours after injection: (fig. 12)

i) Proximal portion

Almost all the cells of the proximal portion show increased activity just as those in group b). Findings of this group, however, are characterized by the existence of swollen cells (fig. 13), cytoplasm of which shows reduced activity of various degree, weakest, weak and moderate. In the projected cytoplasm of these swollen cells, granules of strong activity can be observed and, in addition, their basal striation which is to show strong activity is almost entirely disintegrated to consist of short rodlets and granules. These rodlets and granules have increased in their number and show strong activity. The granules can be found not only in the cytoplasm between nucleus and brushed border but also in its basal part.

ii) Distal portion (fig. 14).

Marked alternations in activity are observed in the cells near the proxmal portion. Brush border shows striking increased activity. Cytoplasm also shows increased activity especially in its part between nucleus and free surface or facing to the lumen. This part of cytoplasm contains granules showing greatly strong activity.

Compared with group b), the number of rodlets in cytoplasm is increased. Basement membrane shows activity of the same degree with those in group b).

d) 4 hours after injection (fig. 15).

i) Proximal portion.

Alternations in alkaline phosphatase activity are less marked in this group than in group b), c), that is, the number of cells which show activity so strong as those in group b), c), is decreased in this group. As the number of swollen cells is also decreased, the closed lumen of tubules is observed less often. 
A few cells of the proximal portion near glomeruli still show markedly increased activity, but their cells show merely. a little increased activity. Brush border including the cytoplasm between nucleus and brush border shows strikingly strong activity, but the basal fart of the cytoplasm shows moderate or sometimes weak activity. Granules showing marked activity in the cytoplasm between nucleus and brush border can be observed also in this group. But almost all of these granules found in the basal part of the cytoplasm are not granules, when carefully observed, but short rodlets irregularly arranged.

Basement membrane shows strong activity.

ii) Distal portion.

In this group, no cells can be observed which show activity so strong as demonstrated in group c).

The brush border is thin inspite of its strong activity and the cytoplasm in contact with it shows merely moderate activity; the basal part of cytoplasm also shows moderate activity. Karyoplasm shows sometimes no activity and the nuclear membrane often shows moderate activity. In the cytoplasm between nucleus and brush border, granules of strong activity can be observed. In other part of it, threadlets and rodlets are found irregularly arranged.

Basement membrane shows an activity of the same degree with controls.

e) 6 hours after injection (fig. 16).

i) Proximal portion.

The brush border is thin in this group, although it still shows strong activity.

The lumen of tubules is enlarged and filled with a network of strong activity. The cytoplasm adjacent to the brush border shows strong activity and moderate activity in its basal part.

The number of granules of strong activity in the cytoplasm between nucleus and brush border is decreased and the number of threads showing strong activity is increased contrarily in its basal part of the cytoplasm. In addition to these threads, granules and rodlets can be still observed in the basal part of the cytoplasm.

Basement membrane shows activity of the same degree with control.

ii) Distal portion.

The lumen of the tubules is enlarged and the number of threads in cytoplasm is increased.

Each part of the cells shows an activity of the same degree with 
control.

3) Findings on groups injected with distilled water.

Findings on this group are the same with the control.

C) Activity of acid phosphatase.

1) Control (fig. 17).

i) Proximal portion (fig. 18).

Brush border shows no particulary strong activity. Brush border as well as the cytoplasm between nucleus and brush border shows strong activity. The basal part of cytoplasm shows moderate activity, leaving a narrow zone of weak activity around the nucleus.

Karyoplasm shows strong activity and contains threads and granules of extremly strong activity.

Nucleolus sometimes shows strong activity.

The basement membrane shows moderate and sometimes strong activity.

Threads which show strong activity can be seen regularly arranged parallel to the cell axis in the cytoplasm. But the projected part of cytoplasm of swollen cells (fig. 19) is in lack of these threads or of any particle and shows sometimes almost negative activity. The nucleus of the swollen cells is elevated.

ii) Distal portion (fig. 20).

Just as in the case of aikaline phosphatase, each part of the cells shows weaker activity than that of cells of the proximal portion. The brush border shows no particularly strong activity but shows, as well as the cytoplasm between nucleus and brush border, just moderate activity.

The lumen of tubules contains a network of moderate or weak activity.

The basal part of the cytoplasm shows weak activity and leaves a narrow ring showing almost negative activity around the nucleus. Roughly constructed basal striation existing from the nucleus level downward shows moderate activity. The construction of the basal striation becomes more rough gradually in the cells nearer to Hen le's loop.

Basement membrane shows moderate activity.

2) Finding on groups injected with alloxan.

a) 30 minutes after the injection

i) Proximal portion (fig. 21).

The nucleus shows increased activity especially in the nuclear membrane and nucleolus. Other findings are the same with the control. 
ii) Distal portion (fig. 22).

Nucleus shows increased activity especially in nuclear membrane and nucleolus. Other findings are the same with controls.

b) 1 hour after the injection (fig. 23).

i) Proximal portion (fig. 24).

All the parts of cytoplasm including nucleus show strikingly strong activity. The nucleus is merely differentiated from cytoplasm by a narrow zone of cytoplasm, showing relatively weak activity arround it.

Cytoplasm showing strong activity contains short rodlets or threads. Granules showing activity can be found more in the cytoplasm between nucleus and brush border than in its basal part.

ii) Distal portion (fig. 25).

Cells of the distal portion show more increased activity than the controls. Cytoplasm shows moderate activity even in its basal part and leaves a ring shaped zone showing relatively weak activity arround the nucleus. The lumen of tubules is somewhat enlarged and contains a network of strong or moderate activity.

Basal striation irregularly constructed can be seen in the cells near the proximal portion.

The basement membrane shows partially strong and partially moderate activity.

c) 2 hours after injection (fig. 26).

i) Proximal portion (fig. 27),

Compared with control, almost all the cells of this portion show reduced activity. But findings on this group are characterized by the existence of many swollen cells ; a pirt of their cytoplasm is projected into the lumen of tubules so much that the lumen seems to be almost closed.

Cytoplasm generally shows moderate activity. But the activity is relatively strong in its basal part and especially weak or sometimes almost negative around the nucleus.

Karyoplasm showing moderate activity contains thread-like or granular particles and nucleolus which show strong activity.

The projected part of cytoplasm of the swollen cells shows almost negative activity and contains granules of strong activity. Their nuclei are normally situated and larger than the control.

ii) Distal portion (fig, 28).

Compared with the control, each part of the cells shows reduced activity and the lumen of tubules is enlarged. Cytoplasm shows weak 
activity especially in its basal part and sometimes negative activity around the nucleus.

Basal striation can be observed in the cells near the proximal portion.

The basement membrane shows weak activity.

d) 4 hours after injection.

i) Proximal portion.

The acid phosphatase reaction is more reduced than in group c) and swollen cells also decrease in their number.

Cytoplasm shows moderate or weak activity which is relatively strong in its cytoplasm between the nucleus and brush border. Granules showing strong activity can be observed in the cytoplasm between nucleus and the brush border and short rodlets showing strong activity irregularly arranged in its basal part.

Basement membrane shows partially moderate and partially weak activity.

ii) Distal portion.

Each part of the cell, especially its cytoplasm, shows greatly reduced activity. The nucleus shows weak activity, but the nuclear membrane alone shows moderate activity. Granules showing moderate activity are seen roughly scattered in the cytoplasm. The basement membrane shows weakest activity.

e) 6 hours after the injection.

i) Proximal portion (fig. 29).

The lumen of tubules is enlarged and contains a network showing strong or moderate activity. The degree of activity in each part of cells is the same with the controls. Fine granules can be seen scattered among threads and rodlets in cytoplasm.

ii) Distal portion (fig. 30).

The lumen of tubules is more enlarged than those of group d) and contains a network showing moderate or weakest activity.

3) Findings on groups injected with distilled water.

Findings on this group are the same with those of the control.

D) Reactions of PAS positive substance and glycogen.

I) Control.

a) PAS positive substance (fig. 31).

i) Proximal portion (fig. 32).

Because of extremly strong reaction, the brush border looks to consist of fine rodlets or of stripes arranged in close longitudinal lines. The boundary between each cell is indistinct. Reactions in 
cytoplasm are generally weak. Reactions of different degree can be observed, however, according to the different part of cytoplasm. The basal part of cytoplasm stains weak. Basal striation, stained relatively deep, can be observed to be arranged parallel to the longitudinal cell axis from the nucleus level downwards. The cytoplasm between nucleus and brush border stains rather deeply and contains fine or large granular particles staining intense.

The brush border of swollen cells is thin or has sometimes disappeared. In such a case both the lumen of tubules and the brush border contain stainable granules.

The basement membrane stains very deeply.

ii) Distal portion (fig. 33).

The brush border is stained more intense than those of the proximal portion, that is, it is thicker and consists of stripes more deeply stained. But the brush border of swollen cells, just as in the proximal portion, is thin or has sometimes disappeared. The cytoplasm stains weakly and the nucleus is left unstained. Fut the basement membrane stains very deeply. In the basal part of the cytoplasm, striation is observed stained moderately, which becomes gradually rough in the cells nearer to $\mathrm{Hen}$ l e's loop. As the striation becomes rough, stainable granules come to increase in their number so much as to be scattered in the whole part of the cytoplasm. Some of these granular particles gathering in the cytoplasm between nucleus and brush border are large and stain relatively intense.

b) On diastase digestion.

Findings on the sections stained by the PAS method on digestion with $1 \%$ diastase solution at $37^{\circ} \mathrm{C}$ for an hour are as follows:

i) Proximal portion (fig. 34).

The brush border shows slightly reduced staining, that is, the longitudinal stripes it consists of become rough. The thickness of the brush border also slightly decreases. But stainable granules can still be observed in the cytoplasm between nucleus and the brush border. Cytoplasm is slightly digested, but the basement membrane is left unchanged.

ii) Distal portion (fig. 35).

Cytoplasm shows a little decreased staining, that is, it is slightly digested. The brush border has become thinner and stains more weakly, which indicates that the brush border of this portion is digested to a more advanced degree than that of the proximal portion.

Stainable granules remain undigested. 
Basement membrane is left unaltered.

II) Groups injected with alloxan.

1) 30 minutes after injection.

a) PAS positive substance.

i) Proximal portion (fig. 36).

Compared with the control, the brush border, showing decreased staining has become thinner and its longitudinal stripes have become rough. Reaction in cytoplasm is also slightly reduced.

The basement membrane stains by the sarre degree as the control.

ii) Distal portion (fig. 37).

Compared with the control, reaction in the brush border is slightly reduced, just the same as that of the proximal portion. Thickness of brush border also decreases.

The basement membrane stains just as much deeply as the control.

b) On diastase digestion.

The stainability is not altered in diastase digestion.

2) 1 hour after the injection.

a) PAS positive substance.

i) Proximal portion (fig. 38).

Cells are slightly swollen. The brush border is thicker than that of group 1) and thinner than the control; it stains a little more weakly and its stripes are rough. Cytoplasm is stained as much weakly as the control. Fine stainable granules in the cytoplasm between nucleus and the brush border increase in their number. Granules are found also in its basal part.

The basement membrane stains as much deep as the control.

ii) Distal portion (fig. 39).

The lumen of tubules is enlarged and contains a PAS positive network. The brush border is thicker than that of group 1) and thinner than the control; it stains more weaker than the control and looks to be roughly constructed. Cytoplasm and basement membrane are stained to the same degree as the control.

b) On diastase digestion.

i) Proximal portion

The brush border has become extremly thin. In several parts of the brush border, reaction is greatly reduced and sometimes negative. Cytoplasm is slightly digested. Reaction in the basement membrane is also reduced. These finding indicate, that alternations in reaction of PAS positive substance in diastase digestion is greater than the 
control.

ii) Distal portion

Each part of the cells is digested as much as that of the cells in the proximal cortion.

3) 2 hours after the injection.

a) PAS positive substance (fig. 40).

i) Proximal portion (fig. 41).

Compared with the control, reaction in the brush border is greatly increase to make it deeply stainable. It increases in its thickness and its structure becomes indistinct. Reaction in cytoplasm is moderate, that is, it stains more deeply than the control. In the basal part of the cytoplasm threads and rodlets staining relatively deeply can be observed. And in the cytoplasm, between nucleus and brush border; large granules which are strongly stainable can also be observed.

Many cells, swollen and projected into the lumen of the tubules, are recognized in this group. Reaction is reduced in the projected part of the cytoplasm of these cells.

Reaction in basement membrane is stronger than in the control.

ii) Distal portion.

The lumen of tubules is as much enlarged as that in group 2) and filled with PAS positive substance (fig. 43), sometimes with a network (fig. 42).

The brush border is thick and stains deeply. Rodlets within it stain very deeply and are arranged in close longitudinal lines. These findings indicate that reaction in the brush border is stronger than in the control. Reaction in cytoplasm is stronger than in the control and it stains moderately. Many granules stained deeply can be observed in the cytoplasm between nucleus and the brush border. Fine grauules and basal striation stained relatively deep can be observed in the basal part of cytoplasm.

Reaction in the basement membrane is stronger than in the control.

b) On diastase digestion.

i) Proximal portion (fig. 44).

Reaction in the proximal portion in diastase digestion is remarkable reduced. The brush border is thin and shows weak reaction and its stripes become more indistinct. Cytoplasm and the basement membrane also show reduced reaction.

ii) Distal portion (fig. 45)

This portion is digested to a more advanced degree than the pro- 
T. Kashimura

ximal portion and shows remarkably reduced reaction. The PAS positive substance in the lumen of the tubules is also ent rely digested and only a part of it remains as a network stained weakly. Reaction in cytoplasm is very weak and that in the basement membrane is also reduced.

4) 4 hours after the injection.

a) PAS positive subs!ance.

i) Proximal portion (fig: 46)

Swollen cells are decreased in their number. The brush border is thinner than the control and shows strong reaction. Its stripes are indistinct but sometimes recognized as longitudinal lines of fine rodlets. The boundary between brush border and the cytoplasm always shows strong reaction, even when, the brush border of some cells show a partial weak reaction. Cytoplasm and the basement membrane show reaction of the same degree as the controls, but the basal part of the cytoplasm still contains short rodlets or fine granules stained moderately. In the cytoplasm between nucleus and the brush border, many relatively large granules showing strong reaction can be observed.

ii) Distal portion (fig. 47).

The lumen of the tubules is also seen enlarged in this portion and sometimes filled with PAS positive substance stained markedly. The PAS positive substance, however, is decreased in its amount and often remains merely as a network. Reaction in almost all of the brush borders of cells surrounding a lumen which is filled with PAS positive substance is reduced. And in the cytoplasm of these cells, relatively large granules stained deeply are observed between the nucleus and the brush border and many granules in its basal part. Cytoplasm itself stains as deeply as the control. Brush border of cells surrounding a lurren of tubules containing network of PAS positive substance is thinner than the control, and has distinct longitudinal stripes; cytoplasm of these cells has basal striation stained moderately. Reaction in both cytoplasm itself and the basement membrane is of the same degree as the control.

b) On diastase digestion.

i) Proximal portion.

Cells are digested to almost the same degree as those in group 2).

ii) Distal portion.

Cells are digested to almost the same degree as those in group 2). 
The brush border of the cells surrounding the lumen of tubules which contains a network faintly stained is very thin and rough.

5) 6 hours after the injection.

a) PAS positive substance (fig. 48).

i) Proximal portion.

Reaction in each part of the cell is reduced in comparison with the control. The brush border decreases in its thickness. Its stripes are rough and often indistinct. Cytoplasm also shows decreased staining. Basal striation stains distinctly, but granules in the cytoplasm between nucleus and brush border decrease in their number. The basement membrane only is stained as deeply as the control.

ii) Distal portion.

Findings are the same as with the control.

b) On diastase digestion.

Findings are the same as with the control.

III) Groups injected with distilled water.

Findings are the same as with the control.

E) Protein.

I) On Hg-BPB method.

1) control.

i) Proximal portion (fig. 49).

The brush border is hardly stained. Almost all the lumina of tubules are vacant but some of them contain very little amount of irregularly shaped substance, staining faintly. Karyoplasm stains moderately and contains threads and granules. Nucleolus stains deeply. Cytoplasm stains deeply and most deeply at its other basal part. But it stains less deep arround the nucleus than any part of the cytoplasm. In the basal part of the cytoplasm, ralatively large threads and rodlets stained distinctly are arranged in close lines along the longitudinal cell axis from the bottom of the cell upward to the nucleus level. Above the nucleus short rodlets and granules can be observed to be stained deeply. In swollen cells, apical parts of their cytoplasm stain faint, their nuclei are elevated, and deeply stainable particles above the nuclei increase in their number.

ii) Distal portion (fig. 50).

The lumen of tubules is often larger than that in the proximal portion. Cytoplasm stains most deeply at its basal part, just as the same with the proximal portion, and leaves a narrow zone stained less deeply arround the nucleus. Karyoplasm stains less deeply than that observed in the proximal portion and contains fine granules and 
threads stained distinctly. In the basal part of cytoplasm rodlets and threads can be observed to be stained distinctly and scattered from the nucleus level downward just as in the proximal portion. But they are more roughly arranged than those in cells of the proximal portion and gradually decrease in their number in the cells nearer to Henle's loop. As these threads and rodlets in the basal part of their cytoplasm come to decrease in their number, granules and granular panticles larger than the granules come to be found not only above the nucleus but downwards in the basal part of cytoplasm. These alternations in character and position of the particles within the cytoplasm may possibly be regarded as corresponding with alternations of the mitochondrial function. The brush border is observed to be thin and consisting of short threads and rodlets roughly arranged longitudinally. Swollen cells are recognized also in this portion. The projected part of their cytoplasm shows decreased staining and looks lighter. In such cells granules of various size stained moderately can be observed even in its basal part.

2) Groups injected with alloxan.

a) $\mathbf{3 0}$ munutes after injection.

i) Proximal portion.

Finding are almost the same as with the control. But the extremely thin brush border can be observed to be consisting of threads or of rodlets which are arranged vertically to the free surface of cytoplasm and show various activity, from moderate to strong.

ii) Distal portion.

Granules stained deeply increase in their number in cells of this portion. The increase in the number of such granules is most marked especially in the cytoplasm between nucleus and brush border. The brush border is thinner than the control, but its longitudinal stripes come to be arranged closer at some part of it, which makes it stain partially deep. Compared with the control, the number of swollen cells increase and their cytoplasm stained less deeply contains granules with moderate or deep staining.

b) 1 hour after injection.

i) Proximal portion.

No marked alternations in the degree of staining can be observed. Short rodlets and many granules are observed in the basal part of the cytoplasm and they stain very deeply. Besides swollen cells with elevated nucleus, swollen cells without elevation of nucleus appear in this group, which can not be observed in the control. The nucleus 
of the latter is larger than that of the control, whose karyoplasm stains faint. But their cytoplasm stains hardly and looks lighter.

ii) Distal portion.

Findings on this portion is characterized by the increase in the number of rodlets stained deeply in the basal part of the cytoplasm and the appearance of swollen cells with large nucleus stained faintly.

c) 2 hours after injection.

i) Proximal portion.

Swollon cells with large nucleus stained faintly increase in their number. Basal striation which is usually recognized as thread-like structure stained deeply is almost disintegrated. Instead of the disintegrated basal striation, many short rodlets come to appear irregularly arranged in the basal part of the cytoplasm. Granules stained deeply can be observed also in the basal part of the cytoplasm.

ii) Distal portion.

Just as the same with proximal portion, swollen cells with large nucleus stained faintly show increase in their number. But, controversely, other cells decrease in their height to make the lumen of tubules larger; in the cytoplasm between nucleus and the brush border of these cells many granules can be observed and in its basal part thread-like structures stained deeply.

d) 4 hours after injection.

i) Proximal portion.

The number of swollen cells slightly decreases. Granules stained deeply in the basal part of the cytoplasm also decrease in their number and, instead of them, rodlet 3 and threads increase in their number. The brush border is very thin. In some parts of it, short longitudinal lines can be observed to be deeply stained and irregularly arranged.

ii) Distal portion.

Many of the lumina of tubules are enlarged. The thin brush border can be observed to be consisting of rough stripes stained deeply. In the cytoplasm, granules stained deeply are observed even in its basal part. And in the basal part of the cytoplasm, threads and short rodlets irregularly arranged can also be observed besides the granules.

e) 6 hours after injection.

i) Proximal portion.

No swollen cells are observed. Cells of this portion decrease in their height to make the lumen of tubules larger. The brush border 
is extremly thin. The number of granules in the cytoplasm between nucleus and brush border decreases and that of rodlets and threads stained deep in its basal part increases. The lumen of tubules contains very little amount of substance which stains deeply.

ii) Distal portion.

The lumen of tubules is enlarged more than those in group d). The brush border is thin and stains partial moderately and partial deeply. Granules stained deep in cytoplasm seem to have increased in their number.

3) Groups injected with distilled water.

Findings are almost the same as with the control.

II) On alloxan-Schiff method.

On Hg-BPB method, as above mentioned, it is observed that cells of the proximal portion are stain more deeply than those of the distal portion, both in the control and in groups injected with alloxan or with distilled water. On alloxan-Schiff method, however, cells of both the proximal and distal portion stain equally. Alternations in the distribution, and appearance of intracellular particles, according to various intervals after injection, can be observed in this method so clearly as in the Hg-BPB method. It can be observed, too, just as in the Hg-BPB method, that no alternation in the degree of staining of them occurs according to different intervals after injection.

\section{Discussion.}

So many observations on the alternations in kidney tissue caused by administration of toxic substances have so far been made by various authors, that they can not shortly reviewed here. But, because of lack of a suitable method, as historically reviewed by $\mathrm{Mc} \mathrm{M}$ a n u s (1955), the classical cytochemical study of kidney tissue could not but be linitted within a certain range either to prove the existence of several substances in cells of urinary tubules, such as glycogen on Best's carmin method, droplets of fatt heterogenously appearing in various kinds of diseases on sudan III staining, or to attempt to examin the construction of droplets found in the absorption phase of proteins.

Since Gomori (1941) found a method to demonstrate alkaline phosphatase reaction in tissue, new advanced methods for histo- or cytochemistry have been found in succession to make the recent study possible. Histo- or cytochemical studies on the effect of toxic subs- 
tances in the kidney are, however, few except a cytological study on the effect of injection of thiazol by $\mathrm{Mi}$ y os hi (1937), histochemical studies on the effect of mercuric chloride, potassium bichromate, benzol, barbitunate and chloral hydrate by $\mathrm{M}$ a e d a (1951), cytological studies on the effect of D.A.B. and salvarsan by Kog a (1953), cytological studies on the effect of potassium chromate, carbon tetrachloride and mercuric chloride by $\mathrm{K} \mathrm{a} \mathrm{w} \mathrm{a} \mathrm{i}$ (1954), cytological studies on the effect of dl-serine and quick silver by Wachste in and $M$ eisel (1954). No report on the effect of alloxan has yet been published.

Functional classification of proximal tubule:

It has been confirmed by many observations and experiments that each part of the urinary tubule is consisting respectively of cells with perculiar construction and does not function equally. Even in recent time, Sjöstrand and Rhodin (1953), Pease (1955) and B a rg ma n et al. (1955) worked the details in morphology of the urinary tubule with electron microscope. But there remain, still now, many problems unsolved in morphology and physiology of the urinary tubule.

So far as the proximal tubule is concerned, each part of it is not equal either morphologically or functionally, and it can be classified in various manners. L o $\mathrm{gle} y$ and $\mathrm{F}$ is $\mathrm{ch}$ er (1954) observed that PAS positive substance and alkaline phosphatase are distributed contrary to each other in the proximal tubule of the vertebrates such as mammals, birds and amphibia, and pointed out that the tubule can be devided into two different parts which do not necessarily correspond to its old classification, convoluted parts and straight parts. They thought it more important to devide the proximal tubule into two parts, P I (a part proximal to glomeruli) and P II (terminal part following P I). Möllendorf (1930) observed in 20 mice that terminal part of pars recta of proximal tubule can be differentiated morphologically from other parts by the peculiar aspect of its brush border. Z immerman (1911) found that epithelial cells of the upper part and lower part of the proximal tubule differs from each other in their contour. Footh and Grafflin (1938) confirmed $\mathrm{Z}$ immerman n's observation and Graff 1 in (1937) reported that the proximal tubule of fish can also be divide into two parts.

Besides these authors who devided the proximal portion into two parts, some authors devided it into three parts. Observing shapes and arrangement of mitochondria as well as the effect of various 
medicanments on them, Mi y os hi $(1936,1937), \mathrm{K}$ og a (1953) and $\mathrm{K}$ a w a $\mathrm{i}$ (1955) divided the proximal tubule of rat's kidney into three portions, proximal portion near glomeruli, distal portion near Henle's loop and middle portion between the two. Sunaga (1955) in his cytological studies on the proximal tubule of human kidney, supported the idea of Carlier (1900) and Ferrat a (1905) to devide the proximal portion into two parts, straight parts and convoluted parts, deviding the former further into three parts.

The difference among the activities of alkaline phosphatase, acid phosphatase, PAS positive substance and proteins according to the different part of the proximal tubule, as is the result of this study, indicates that the proximal tubule should be divided into two parts. This conclusion agrees with Longley and Fis cher's view.

Alkaline phosphatase: Numerous reports on normal distribution of alkaline phosphatase in the kidney and on alternation is its activity under various experimental conditions agree that alkaline phosphatase reactions in normal kidney tissues are observed in its cortical zone and especially in cells of the proximal tubule. Longley and Fis cher (1954) reported that alkaline phosphatase reaction in the proximal tubule was most marked in cells of its proximal portion, connecting the glomerule. In this experiment, alkaline phosphatase reaction in the control is marked in the proximal tubule especially in its proximal portion. The most marked reaction was observed in the brush border of the epithelial cells of the proximal portion. Reaction in cytoplasm of these cells was marked in contact with the brush border and relatively reduced in its basal part. Moderate reaction in the nucleus and a strong reaction in the basement membrane were also observed.

Alkaline phosphatase in pathologic or experimental condition: Reduced alkaline phosphatase reaction was observed in experimental hydronephrosis by. W a chstein (1946) and $\mathrm{Eränkö} \mathrm{and} \mathrm{Ni} \mathrm{e} \mathrm{m} \mathrm{i}$ (1954); in the ischemic kidney on ligation of renal artery by Go e be 1 and Puchtler (1954). Reduced activity of stainable alkaline phosphatase was observed in cases with exstirpation of the epithyroid by Eger and Gellers (1953); in cases administered with methylthiouracil by Meier (1952); in experimental shock by Berg and L e vin s o n (1952). M a e d a (1951) observed that activity of alkaline phosphatase increased in epithelial cells of collecting tubules, when the epithelial cells of the proximal tubule were injured by administration of mercuric chloride, potassium bichromate, benzol, barbiturate and 
chloral hydrate. K u b o (1954) observed slight increase in the activity of alkaline phosphatase in the cortical zone of the kidney in adrenectomized animals, that is, activity in the brush border of cells of the proximal tubule increases and even the glomeruli which show negative activity in normal cases show moderate activity.

In groups injected with alloxan in this experiment, though they are treated with single injection and observed within a short time after injection, it is observed that activity in almost all the epithelial celis of the proximal tubule increases initially and then decreases after the maximal point is reached. In groups injected with alloxan, in order to differentiate these alternations from those caused by infusion water itself, no alternation in alkaline phosphatase reaction is observed.

Acid phosphatase: Normal distribution of acid phosphatase, as has been reported by E r ä $\mathrm{k}$ ö and Nie m i (1954), is limitted within the cortical zone of the kidney, especially in the proximal tubule of its urinary tubules. But Wachstein (1955) found that normal distribution of acid phosphatase in nephron varies with the difference of the species of animals; in mice, reaction of acid phosphatase is marked in the proximal portion of the proximal tubule, weak in the glomerulus and negative in other parts of the nephron; in rat, rabbit, cat and dogs, slight reaction was observed in various parts of the nephron including Henle's loop, in addition to the marked reaction in the proximal tubule.

In this experiment, acid phosphatase reaction was observed in almost all the cells of the proximal tubule and especially marked in the cells of its proximal portion. In these cells, the strongest reaction was observed in the brush border and a part of the cytoplasm in contact with it. Contrary to the case of alkaline phosphatase, reaction in the nucleus is strong. Palade (1951) offered a question, wether this reaction in the nucleus is essentially fermental.

Acid phosphatase under various experimental conditions : - Reduced reaction in experimental hydronephrosis was reported by $\mathrm{Eränk. \ddot { }}$ and $\mathrm{Niemi}$ (1954) and in cases orally administered with thiouracil by $\mathrm{Mei}$ e (1952). Increased reaction was observed by $\mathrm{Marsh}$ and Dra b kin (1947) in the kidney of animals with alimentary hyperglycemia.

The result of this experiment shows that acid phosphatase reaction is initially reduced below control level after injection of alloxan and then gradually increased to control level. But these alternations 
are not so marked as in the case of alkaline phosphatase.

PAS positive substance: PAS reaction is regarded as indicating the existence of polysaccharides. Numerous observations and reports have been made on PAS positive substance in tissue. On normal distribution of PAS positive substance in the kidney tissue, W a c h ste in (1955) reported that cytoplasm of epithelial cells of proximal tubule stains faintly in other parts than the basement membrane and the brush border stains more deeply than cytoplasm. This confirms $\mathrm{Ku} \mathbf{u}$ o's observation (1954) that the brush borders of cells of the proximal tubule stains most deeply. Lon g le y and F is c her (1954) reported that distribution of PAS positive substance varies with the species of animals; in mice, it was distributed more densely in the brush border in cells of distal portion than in those of the proximal portion and, in cat, to the contrary.

In this experiment PAS reaction is positive in all the cells of the proximal tubule and most markedly in their brush border. Stained distinctly, the brush border is found to be consisting of extremly fine rodlets or of stripes closely arranged parallel to the longitudinal cell axis. The brush borders in the distal portion with deeply stained close stripes are thicker and stain more deeply than those in the proximal portion. Protoplasm of cells of both, the proximal and distal portion stains equally. Specimens used for demonstration of PAS positive substance in this experiment is sectioned in thickness of $5 \mu$ as required by $\mathrm{Gr}$ is hm an and $\mathrm{Ch}$ ury (1955).

PAS positive substsnce under experimental condition : K o i (1933) who reported on histological alternations in kidney affected with floridin and insulin found that glycogen in kidney tissue, identified on carmin staining, showed initial decrease and succeding increase in its amount. A o y a m a (1949) who made pathological studies on adults with alloxan diabetes found that glycogen precipitated most markedly in Henle's loop and sometimes so far as in the upper part of collecting tubule. Nag a h a ma (1952), in his pathological study on rabbit with alloxan diabetes, observed glycogen degeneration of the epithelial cells not only of the thick part of Henle's loop but of the proximal portion and middle part too. Sometimes he found glycogen precipita: ted even in the epithelial cells of collecting tubule. $\mathrm{K} \mathrm{u} \mathrm{bo} \mathrm{(1954)}$ reported that no marked alternation occured in the amount of polysaccharide in the kidney tissue of adrenectomized animals. $\mathrm{Ka} \mathrm{w}$ a (1955), in his observation on alternation in polysaccharides in kidney tissue affected by potassium chromate and mercuric chloride, found 
that red staining of the brush border of the cells affected, decreased and that PAS granules appeared in these brush borders. $01 \mathrm{ive} r$ (1954-1955) reported that a great amount of glycogen was found in pars recta in diabetes mellitus and in the ascending limb of Henle's loop in experimental diabetes.

In this experiment on injection of alloxan, PAS reaction is initially reduced and succeedingly increased above control level to be reduced later again. Accoring to what $\mathrm{W}$ a chs te in (1955) described and the results of cytological study on the normal human kidney by S u n a g a (1955), it is believed that existence of glycogen can not be proved in the normal proximal tubule. In this experiment, however, an attempt was made to differentiate glycogen from other substances showing PAS reaction, that is, sections were immersed in 1\% diastase solution for an hour antecedent to PAS staining. In control sections, cyotplasm and the brush border are digested very slightly. But it seemed that the brush border in the distal portion was digested to a more advanced degree than that in the proximal portion. In cases with PAS reaction increased by injection of alloxan, staining of cells was markedly reduced and digestion by diastase was most remarkable. In other cases, the degree of diastase digestion of cells are the same as with the control.

Proteins: According to Wachstein's description (1955) on protein in kidney tissue, protein can be stained deeply in the proximal portion of the proximal tubule and faintly in other parts. Oliver et al. (1954) and L e e (1954) found, by use of cytochemical reactions of various kinds; that absorption of protein by the epithelial cells of the urinary tubule is closely related to the function of the mitochondria in them. They stated that protein which had passed the filter of glomeruli is reabsorbed directly by the epithelial cells of the proximal tubule and that droplets came to appear in these cells, only when the amount or quality of protein exceded or did not match the ability of protein reabsorption of these cells. They stated moreover that these droplets were identified to be a combination of reabsorbed protein and mitochondrial substance and presumed that protein might possibly be treated by enzymes which were abundantly stored in the mitochondria. From such a point of view, they described the reduced staining of protein in the distal portion to the decrease of mitochondria in cells of that portion. Kre ts chmer and Dickerman (1954) found, in animals injected with the white of egg, that droplets were formed in the epithelial cells of the proximal tubule with simultaneous 
dissolution of mitochondria, and pointed out close relations between protein metabolism and mitochondrial function. $\mathrm{Kret} \mathrm{chmer}$ and Ch e r ot (1954) reporied that droplets can be formed in the epithelial cells of the proximal portion of the proximal tubule also by injection of amino acids. Rigas and $\mathrm{Heller}$ (1951) and Seller et al. (1952) reported, however, that protein metabolism was observed diffusely over the cytoplasm.

In this experiment on $\mathrm{Hg}-\mathrm{BPB}$ method, protein is more marked in the proximal portion than in the distal portion. Cytoplasm of the cells of both portions stained most deeply in its basal part.

Since olden times, there have been made various studies on the function of the kidney. Jas s ow in (1925) and Kosugi (1927) stated that epithelial cells of the proximal tubule have two functions i. e. absorption and excretion. Bargmann (1934) and $\mathrm{S} \mathrm{un} \mathrm{a} \mathrm{g} \mathrm{a}$ (1955) considered that epithelial cells of the proximal tubule with the brush border was in the absorption phase and those without the brush border in the excretion phase. Best and T a yl or (1950) have described that reabsorption of water, glucose and other items from the glomerular filtrate is done mainly in the proximal tubule and that alkaline phosphatase which is neccessary for reabsorption of glucose is always found in the proximal portion of the proximal tubule: L ongley and F is cher (1954) stated that almost all the farts of work done by the proximal tubule was reabsorption of water, glucose and other items from the glomerular filtrate and that alkaline phosphatase took part in glucose metabolism. They presume, too, that the brush border plays an important role in the absorption of these substances by the epithelial cells of the urinary tubule. Eg er and Gell e r (1953), observing distribution of alkaline and acid phosphatase, concluded that the former took part in absorption and excretion at the free surface of the epithelial cells of the urinary tubule and the latter in exchange of substances in the interior of those cells. On protein metabolism, L e e (1954), O 1 iver et al: (1954, a, b), Kretchmer and Dickerman (1954), Rigas and Heller (1951) and Seller et al. (1952) reported that protein metabolism took place in cytoplasm and that there must be close relation between reabsorption of protein and the function of mitochondria.

In this experiment, strong reaction of alkaline phosphatase can be observed especially in the brush border and that of acid phosphatase not only in the brush border but also in the cytoplasm. It must be noted, that. sugar is markedly stained not only in the brush border 
but in the basement membrane tod. Protein is found to be deeply stained in the basal part of cytoplasm (with alternations in the construction of basal striation). These facts suggest, that not only the brush border but also the basement membrane plays an important role in sugar metabolism and that cytoplasm takes part in protein metabolism. In groups injected with alloxan, it must be noted that alternations in reaction or staining of alkaline phosphatase, acid phosphatase, polysaccharides and glycogen and that no alternation in staining of protein can be observed. Findings above mentioned show that injection of alloxan gives certain effects on the proximal tubule, but the mochanism of the effects can not be made clear in this experiment.

\section{Conclusion}

The results of this cytochemical study on the effect of alloxan on the porximal tubule of the kidney are as follows:

1) In control, reaction of alkaline phosphatase can be observed in all the cells of the proximal tubule and especially markedly in cells of the proximal portion directly connected with glomerulus. The strongest reaction is observed in the brush border of the cells. After injected with alloxan, the reaction initially increases and later decreases to control level.

2) In control, the reaction of phosphatase is marked in the proximal portion. The strongest reaction is observed not only in the brush border of the cells but in a part of their cytoplasm in contact with the brush border and in their nucleus. After injection with alloxan, the reaction is initially reduced slightly below the control level and increases later to control level. But these alternations in the reaction of acid phosphatase are not so marked as those in alkaline phosphatase.

3) In control, PAS reaction can be observed in all the cells of the proximal tubule. The strongest reaction is observed not only in their brush border but in their basement membrane. PAS reaction is more marked in the distal portion, than in the proximal portion. In groups injected with alloxan, PAS reaction is initially reduced and succeedingly increased to be slightly reduced later again. On diastase digestion, both brush border and cytoplasm are seen slightly digested in the control. But, in groups which were injected with alloxan and showed increased PAS reaction, they are digested to more advanced 
degree. These findings indicate that the slight amount of glycogen observed in the control is increased by injection of alloxan. The increase in the amount of glycogen is marked especially in the brush border of the cells of the distal portion.

4) Protein is stained on Hg-BPB method more markedly in the proximal portion than in the distal portion. The basal part of cytoplasm stained most deeply. No marked alternation in staining of protein can be observed after injection of alloxan.

The author is grateful for the criticism of Prof. T. T a n i g u ch i. This experiment was performed under the project of Instr. M. Ih numa.

\section{References}

1) Ao y a $\mathrm{m}, Z$, and Un o, I. 1949. Pathological studies of the alloxan diabetes. Tr. Soc. Path. Jap. , 38: 151-163.

2) Bailey, C.C and Bailey, O.T. 1943. The production of diabetes mellitus in rabbits with alloxan. J. Amer. med, Ass., 122; 1165-1166.

3) Ba r g ma n n, W. 1934. Untersuchung über Histologie und Histophysiologie der Fischniere. Z. Zellforsch., $21:$ 388-411.

4) Bargmann, W., Knoop, A. and Schiebler Th. H. 1955. Histologische, cytochemische, und elektronenmikroskopische Untersuchungen am Nephron. Z. Zellforsch., $42: 386-422$.

5) B e r g, M. and Le vi n s on, S. A. 1952. Alkaline phosphatase activity of the kidney. A. M. A. Arch. Path., 53:179-186.

6) Best, C.H. and Taylor, N.B. 1950. Physiological basis of medical practice. Williams \& Wilkin Co.

7) Carlier, E. W. 1900 . Note on the presence of ciliated cells in the human adult kidney. J. Anat. Physiol., 37 : 228 (cited from S u n a g a, 1955).

8) Duff, G. L. 1945. The pathology of the pancreas in experimental diabets mellitus. Am. J. Med. Sci., 210: 381-397.

9) Eger, W. and Gell er, H.F. 1953. Über den Einfluss der Nebensshilddrüse auf die phosphatasen der Nieren. Arch. exp. Path. Pharmak. 218: 222-238.

10) Erank 8,0 and $\mathrm{Niemi}, \mathrm{M}$. 1934. Histochemically demonstrable phosphatases in the kideny of hydronephrotic rats. Acta Path. Microbiol. Scand., 35: 357-364.

11) Ferrata, A. 1905. SGllánatomia sullosviluppo e salla funzione del rene. Arch. Ital. Anat., 4: 581 (cited from $S$ u n a g a, 1955)

12) Footh, J.J. and Graff I in, A.L. 1938. Quantitive measurements of the fat laden fat free segments of the proximal tubule in the sephron of the cat and dog. Anat. Rec., 72 : 169.179.

13) Goebel, A. and Puchtler, H. 1954. Über das Verhaiten der histochemisch nachweisbaren alkalischen Phosphatase und 5-Nucleotidase im Sauerstoffmangel und in Niereninfarkt. Virch. Arch. Path. Anat., 326: 119-134.

14) Gomori, G. 1941. Distribution of phosphatase in normal organs and tissues. J. Cell. Comp. Physiol., 17; 71. 
15) Grafflin, A.L. 1937. The structure of the nephron in fishes. Anat. Rec., 68 : $287-303$.

16) Gris h man, E. and $\mathrm{Chury}, J$. 1955. Application of thin sections to the study of glomerular changes in glomerulonephritis. Am. J. Path., 31: 602-603.

17) J a co b s, H. R. 1937. Hypoglycemic action of alloxan. Proc. Soc. exp. Biol. Mied., 37: $407-409$.

18) Jas s o w i n, G. 1925. Zur Histologie der Tubuli contorti der Amphibienniere. Z. Zellfors:h, $2: 741-765$.

19) $\mathrm{K} a \mathrm{wa}$ i, $\mathrm{Y}$. 1955. Toxic substances and the renal tubule of rat. Arch. hist. jap., $8: 19-46$.

20) Kretchmer, N. and Cherot, F. J. 1954. Cellular methanisms of protein metabolism in the nephron. V. The intracellular partition and the incorporation into protein of intravenously injected l-lysine. J, exp. Med., 99: 636-646.

21) Kretchmer, N. and Dickerman, H.W. 1954. Cellular mechanisms of protein metabolism in the nephron. IV. The partition of succinoxidase and cytochrome oxidase activities in the cells of the proximal convolution of the rat after intraperitoneal injection of egg white. J. exp. Med., 99: 629-635.

22) $\operatorname{Kog} a, N$. 1953. Experimental cytological study of kidney-epithelium of the rats. Arch. hist. jap., 5 : 289-326.

23) Ko $\mathrm{i}, \mathrm{M}$. 1933. Uber Verănderungen der Leber und Niere, die infolge der Injektion von Phloridzin und Insulin zum 'Vorscheinkommen. Okayama-IgakukaiZashi, 45 : 2557-2566.

24) Kosa k a, K., Y a tsu kawa, S. and Koide, M. 1951. Study on alloxan diabetes. (IV) On mechanism of initial hyperglycemia caused by administration of alloxan, Fol. Endocrin. Jap., 27: 219-220.

25) Kos u gi, T. 1927. Beitrăge zur morphologie der Nierenfunktion. Beitr. Path. Anat. Allg. Path., 77 : 1-60.

26) $\mathrm{Ku} \mathrm{bo}, \mathrm{Z}$. 1954. Histological studies on phosphatass and polysaccharides of crrtain organs aftor adrenalectomy. Arch. hist. jap., $6: 953-664$.

27) Le e, Y. Ch 1954. Cellular mechanisms of proiein metabolism in the nephron. 1II. The histochemical characteristics of amino acid droplets. J. exp. Med., 99: 621-628.

28) Longley, J.B. and Fi s cher, E.R. 1954. Alkaline phosphatase and the periodic acid Schiff reaction in proximal tubule of vertebrate kidney. Anat. Rec. 120 : $1-17$.

29) Ma da, k. 1951. Histochemical study on alkaline phosphatase in experimental intoxications. Kumamoto-Igakukai-Zashi, 25 : 373-392.

30) Marsh, J.B. and Drabkin, D.L. 1947. Kidney phosphatase in alimentary hyperglycemia and phlorizin glycosuria. A dynamic mechanism for renal threshold for glucose. J. Biol. Chem, 168: 61-73.

31) Miazia, D., Brewer, P.A. and Alfert, M. 1953. The cytochemical staining and measurement of protein with mercuric bromphenol blue. Biol.Bull., 104: 57-67.

32) Meier, A. L. 1952. Der Einfluss der Verabreichung von Methylthiouracil and Thyroxin auf die Phosphatasen verschiedener Rattenorgane. Acta. Anat., 16: 97-107.

38) $\mathrm{McM}$ a nus, J.F.A. 1955. Applications of histoshemistry to elucidation of kidney structrue and function. J. Histochem. Cytochem., 3: 243-245.

34) Miy oshi, R. 1936. Zytologische Untersuchungen der Nierenepitheizellen. Kai- 
bogaku-Zasshi., 9 : 672-692.

35) Mi yoshi, R. 1937. Zytologische Untersuchugen der Nierenepithelzellen. Kaibogaku-Zasshi., 10 : 674-683.

36) von Mollendorff, W. 1930. Der Exkretions apparat. Handbuch der mikroskopischen Anatomie des Mienschen. VII/I : 65-94. Verlag von Julius Springer, Berlin.

37). Na g a h a ma, S. 1951. Study on alloxan-diabetes of Rabbits. Report I : Infuences of adrenalectomy on alloxan-diabetes. Tr. Soc. Path. Jap., 40 : 402-403.

38) $\mathrm{Nag}$ a h a ma, S. 1952. Study on alloxan-diabetes of rabbits. Fol. Endocrin. Jap., 28 : $279-284$.

39) Okamot o, K. 1951. Experimental Pathology of diabetes. Nippon-Isho-Shupan Co. Tokyo.

40) 01 i ver, J. 1944-45. New directions in renal morphology. A method, its results and its future; The $\mathrm{H}$ a r vey lectures., $40: 102-155$.

41) Oliver, J., $\mathrm{M}$ a c Dowe Il, M.C. and L e e, Y.C. 1954a. Cellular mechanism of protein metabolism in the nephron. I. The structural aspects of proteinuria; tubular absorption, droplet formation and the disposal of proteins. J. Exp. Med., 99 : 589-604.

42) Oliver, J., Mioses, N. J., Mĩ a c D owe 11, M. C. and L e e, Y.C. 1954b. Cellular mechanism of protein metabolism in the nephron. II. The histochemical characteristics of protein absorption droplets. J. Exp. Med., 93 : 605-620.

43) O y a, J.C. 1950. Diabéte humain et diabéte expérimental. Schweiz. Med. Wschr. 80 : $1028-1029$.

44) Pa l a d e, G.E. 1951. Intracellular localization of acid phophatase. J. Exp. Mied., 94: 535-547.

45) Pease, D.C. 1955. Fine structures of the kidney seen by electron microscopy. J. Histochem. Cytochem., 3 : 295-308.

46) $\mathrm{R}$ ig a s, D.A. and Helle r, C.G. 1951. The amount of nature of urinary proteins in normal human subjects. $J$ : Clin. Invest., 30: 853-861.

47) Schimizu, N., Handa, N., Handa, Z. and $\mathrm{Kumamot} o, T$. 1951. Histochemical studies of the liver and adrenal gland of alloxan diabetic rabbits. Kaibogaku-Zasshi, $26:$ 74-75.

48) Sellers, A. L., Roberts, S., Rask, I., Smith, S., Marmorston, J. and Goodman, H.C. 1952. An electrophoretic study of urinary protein in the rat. J. Exp. Mied., $95: 465-472$.

49) Sjostrand, F.S. and Rhodin, J. 1953. The ultrastructure of the proximal convoluted tubules of the mouse kidney as revealed by high resolution electron microscopy. Exp. Cell. Res., 4 : 426-456.

50) S mith, H.W. 1951. The kidney, Structure and function in health and disease. Oxford Univ. Press.

51) Sun ag a, Y. 1955. Cytolozical studies on the renal corpuscle and the proximal convolution of the renal tubules in the human kidney. I. Cytological observa. tion on the epithelium of the proximal convclution. Arch. hist. jap., $8:$ 195-215.

52) Suzuki, T. 1912. Zur Morphologie der Nierensekretion unter physiologischen und pathologischen Bedingungen. (cited from $W$ a $c$ h s te i $n, 1955$ ).

53) Wachstein, M. 1946. Influence of experimantal kidney damage on histochemically demonstrable lipase activity in the rat; Comparieon with alkaline phosphatase activity. J. Exp. Med., 84: 25-36.

54) Wachǫtein, ,M 1965. Histochemical staining reactions of the normally func- 
tioning and abnormal kidney. 'J. Histochem. Cytochem., 3: 246-270.

55) W a ch st e in, $M$. and $M$ e is el, E. 1954. Influence of experimental renal damage on histozhemically demonstrable succinic dehydrogenase activity in the rat. Am. J. Path, 30: 147-165.

56) Y a $s$ u a, A. and I chi ka a a, T. 1951. A new cytochemical staining of protein. Medicine and Biology, 19: 197-200.

57) Z i mmerma nn, K.W. 1911. Zur Morphologie der Epithelzellen der Säugetierniere. Arch. Mikr. Anat., 78 : 199-231.

\section{Explanation of figures}

Fig. 1. Cells of the proximal portion of the proximal tubuls stained with Heiden. hain's iron hematoxylin on Zenker-formalin fixation.

Fig. 2. Cells of the distal portion of the proximal tubule stained with Heidenhain's iron hematoxylin on Zenker-formalin fixation.

Fig. 3. Alkaline phosphatase, control.

Fig. 4. Alkaline phosphatase in the cells of the proximal portion, control.

Fig. 5. Alkaline phosphatase in the swollen cells of the proximal portion, control.

Fig. 6. Alkaline phosphatase in cells of the distal portion, control.

Fig. 7. Alkaline phosphatase in cells of the distal portion, control.

Fig. 8. Alkaline phosphatase in groups $\mathbf{3 0}$ minutes after injektion.

Fig. 9. Alkaline phosphatass, 1 hour after injection.

Fig. 10. Alkaline phosphatase in the cells of the proximal portion, 1 hour after injection.

Fig. 11. Alkaline phosphatase in cells of the distal portion, 1 hour after injection.

Fig. 12, Alkaline phosphatase 2 hours after injection.

Fig. 13. Alkaline phosphatase in the cells of the proximal portion, 2 hours after injection.

Fig. 14. Alkaline phosphatase in cells of the distal portion, 2 hours after injection.

Fig. 15. Alkaline phosphatase, 4 hours after injection.

Fig. 16. Alkaline phosphatase, 6 hours after injection.

Fig. 17. Acid phosphatass, control.

Fig. 18. Acid phosphatase, in the cells of the proximal portion, control.

Fig. 19. Acid phosphatase in the swollen cells of the proximal portion, control.

Fig. 20. Acid phosphatase in cells of the distal portion, control.

Fig. 21. Acid phosphatase in the cells of the proximal portion, 30 minutes after injection.

Fig. 22. Acid phosphatase in cells of the distal portion, 30 minutes after injection.

Fig. 23. Acid phosphatase, 1 hour after injection.

Fig. 24. Acid phosphatase in the cells of the proximal portion, 1 hour after injection.

Fig. 25. Acid phosphatase in the cells of the distal portion, 1 hour after injection.

Fig. 26. Acid phosphatase, 2 hours after injection.

Fig. 27. Acid phosphatase in the swollen cells of the porximal portion, 2 hours after injection.

Fig. 28. Acid phosphatase in the cells of the distal portion, 2 hours after injection.

Fig. 29. Acid phosphase in the cells of the proximal portion, 6 hours after injection.

Fig. 30. Acid phosphaease in the cells of the distal portion, 6 hours after injection.

Fig. 31. PAS positive substance, control.

Fig. 32. PAS positive subetance in cells of the proximal portion, control. 
Fig. 33. PAS positive substance in the cells of the distal portion, control.

Fig 34. Cells of the proximal portion on diastase digestion, control.

Fig. 35. Cells of the distal portion on diastase digestion, control.

Fig. 36. PAS positive substance in cells of the proximal portion. 30 minutes after injection.

Fig. 37. PAS positive substance in cells of the distal portion, 30 miuntes after injection.

Fig. 38. PAS positive substance in the cells of the proximal portion, 1 hour after injection.

Fig. 39. PAS positive substance in the cells of the distal portion, 1 hour after Injection.

Fig. 40. PAS positive substance, 2 hour after injection.

Fig. 41. PAS positive substance in the cells of the proximal portion, 2 hours after injection.

Fig. 42. PAS positive substance in the cells of the distal portion, 2 hours after injection.

Fig. 43. PAS positive substance in the cells of the distal portion, 2 hours after injection.

Fig. 44. Cells of the proximal portion on diastase digestion, 2 hours after injection.

Fig. 45. Cells of the distal portion on diastase digestion, 2 hours after injection.

Fig. 46. PAS positive substance in the cells of the proximal portion, 4 hours after injection.

Fig. 47. PAS positive substance in the cells of the distal portion, 4 hours after injection.

Fig. 48. PAS positive substance, 6 hours after injection.

Fig. 49, Protein in cells of the proximal portion on Hg-BPB method, control.

Fig. 50. Protein in the cells of the distal portion on Hg-BPB method, control. 
Plate I
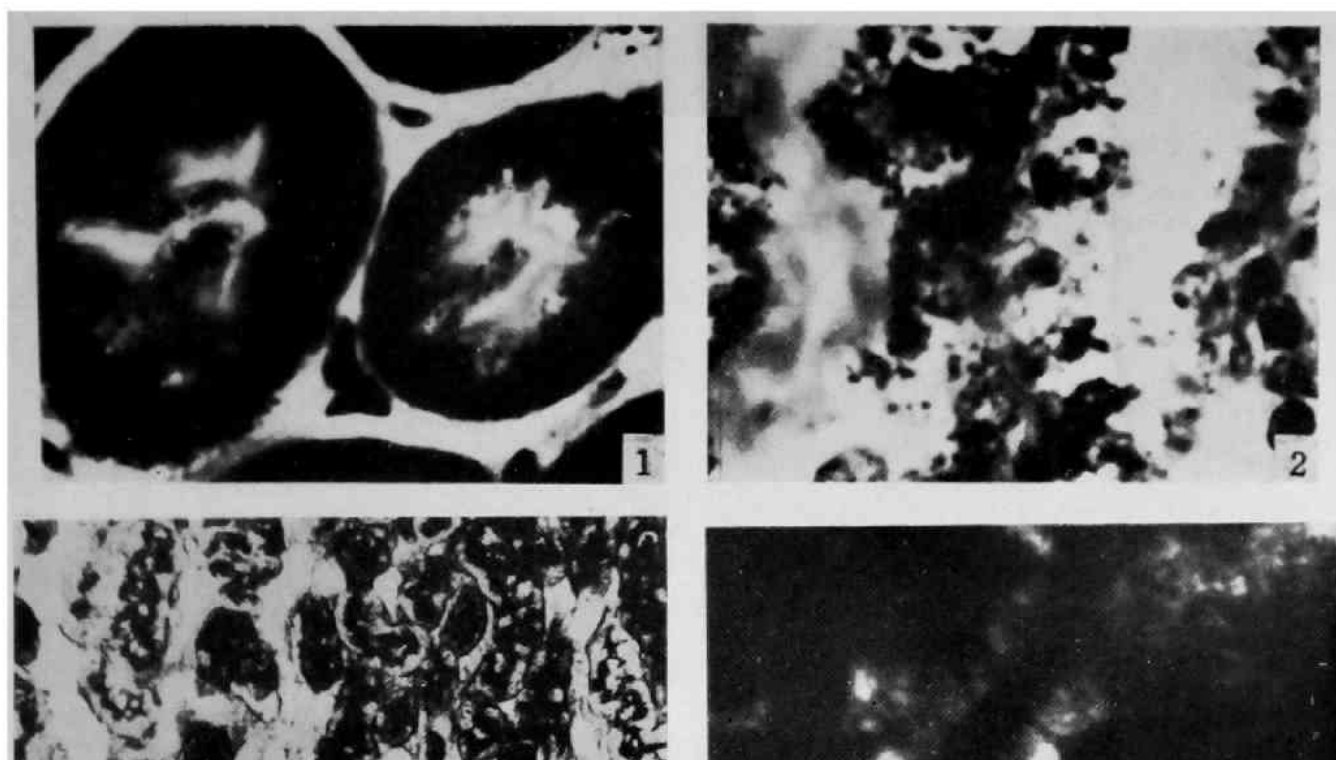
if if (8)

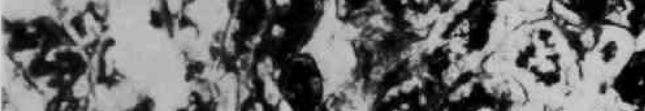

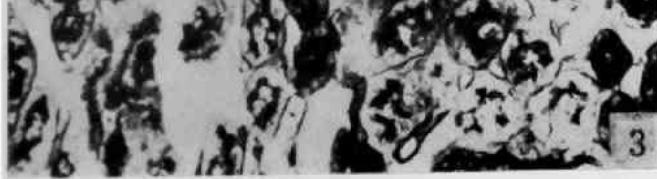
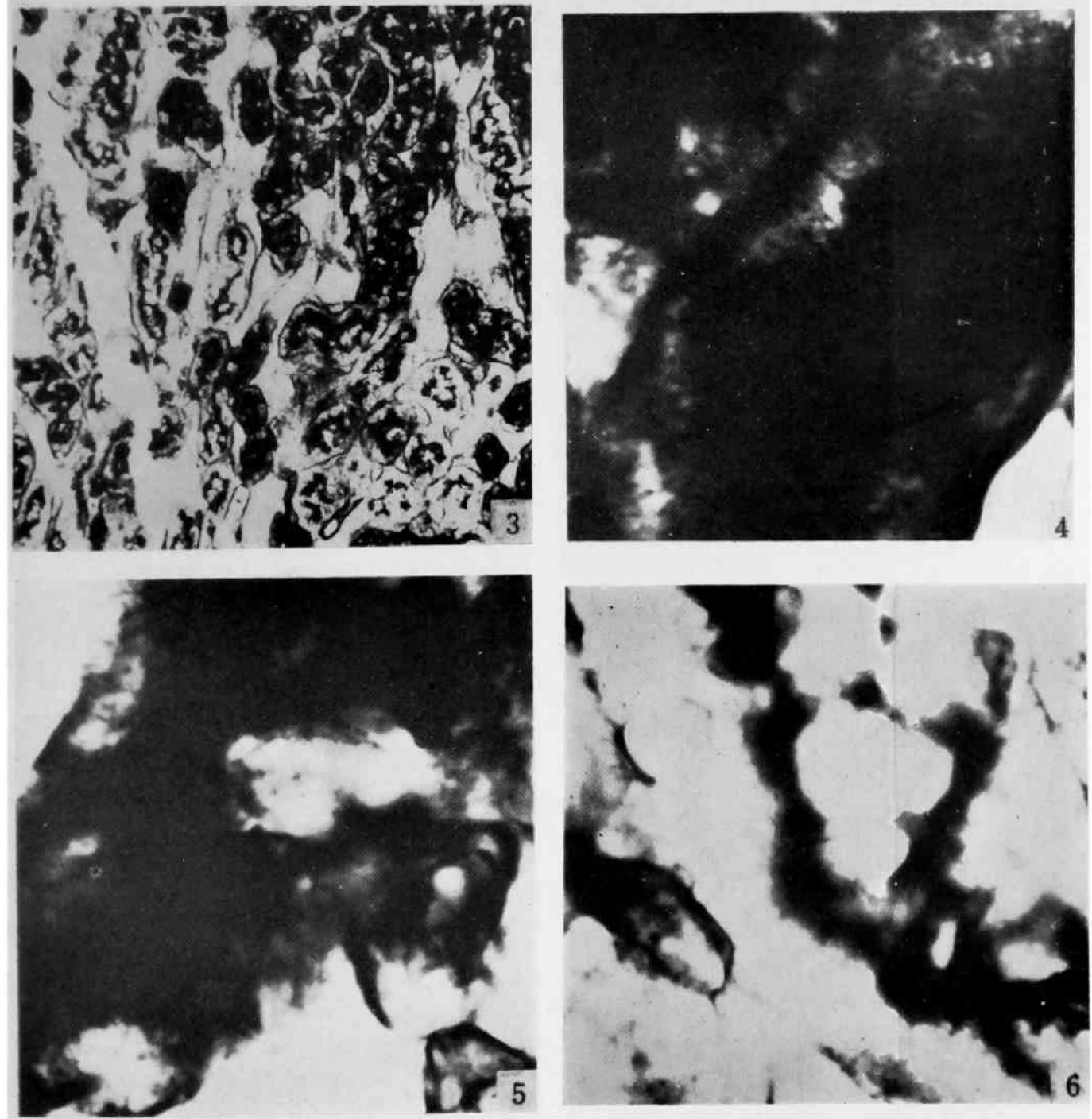

T. Kashimura 
Plate II
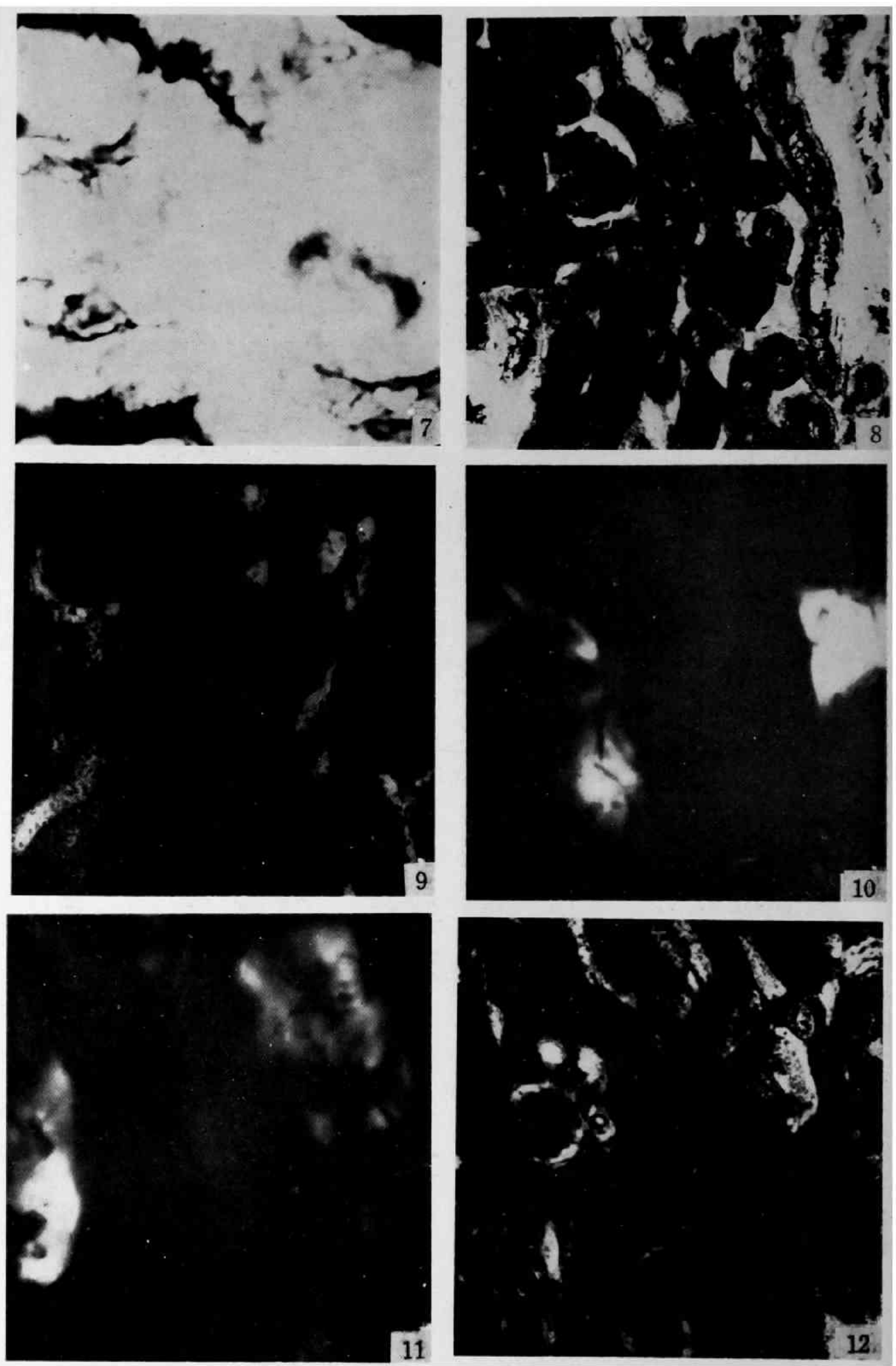

T. Kashimura 
Plate III
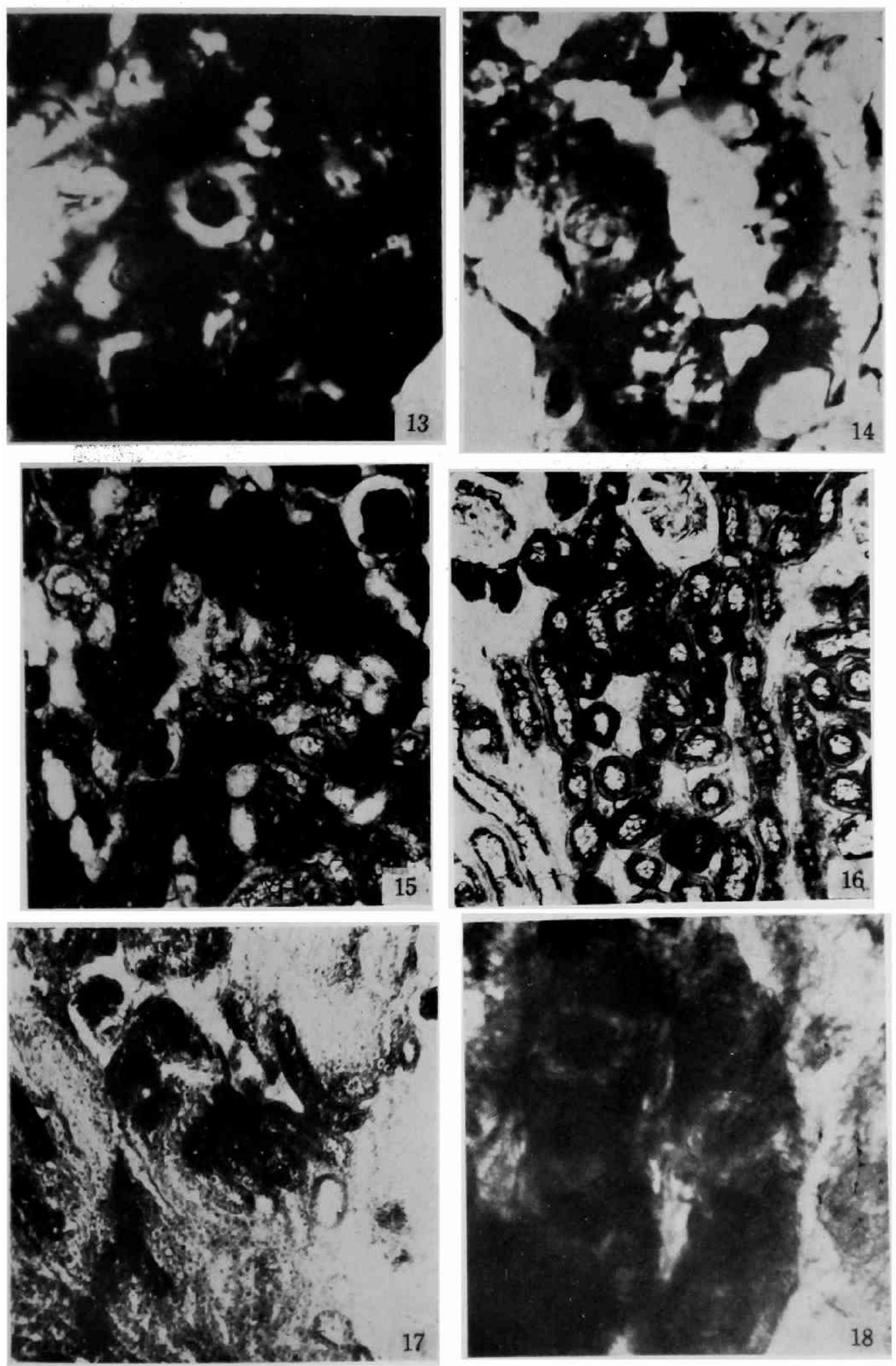
Plate IV
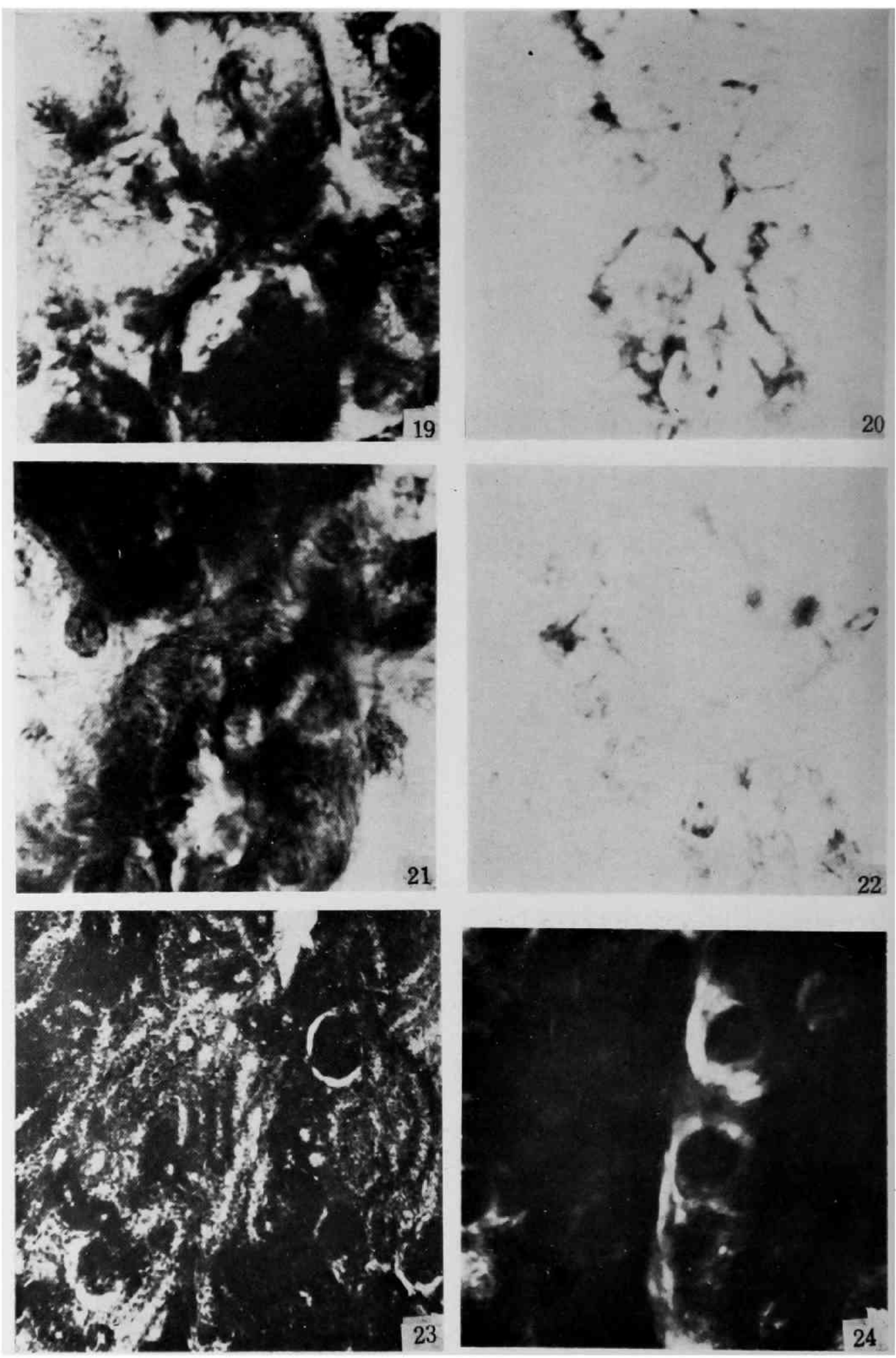

T. Kashimura 

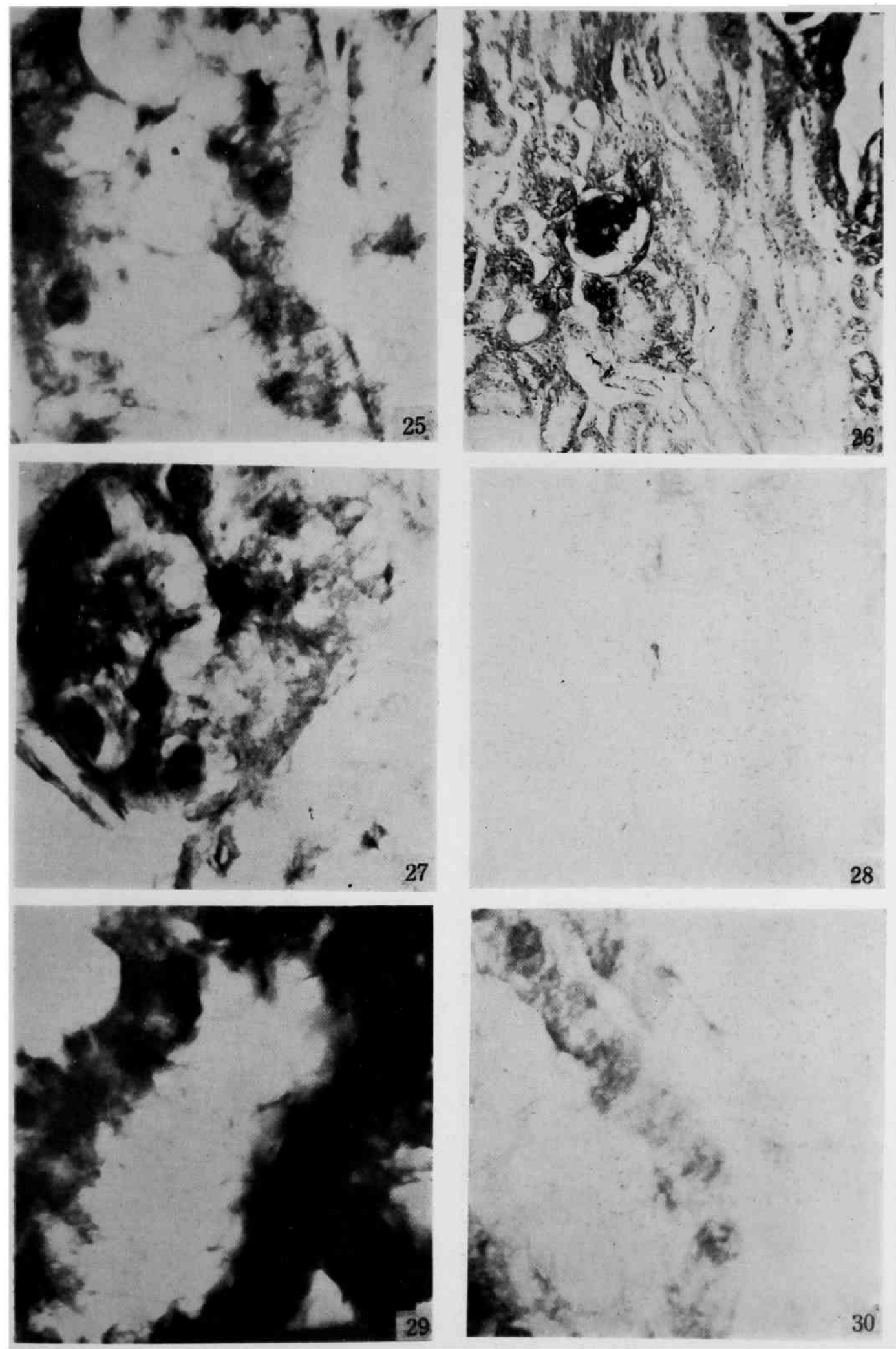

T. Kashimura 
Plate VI
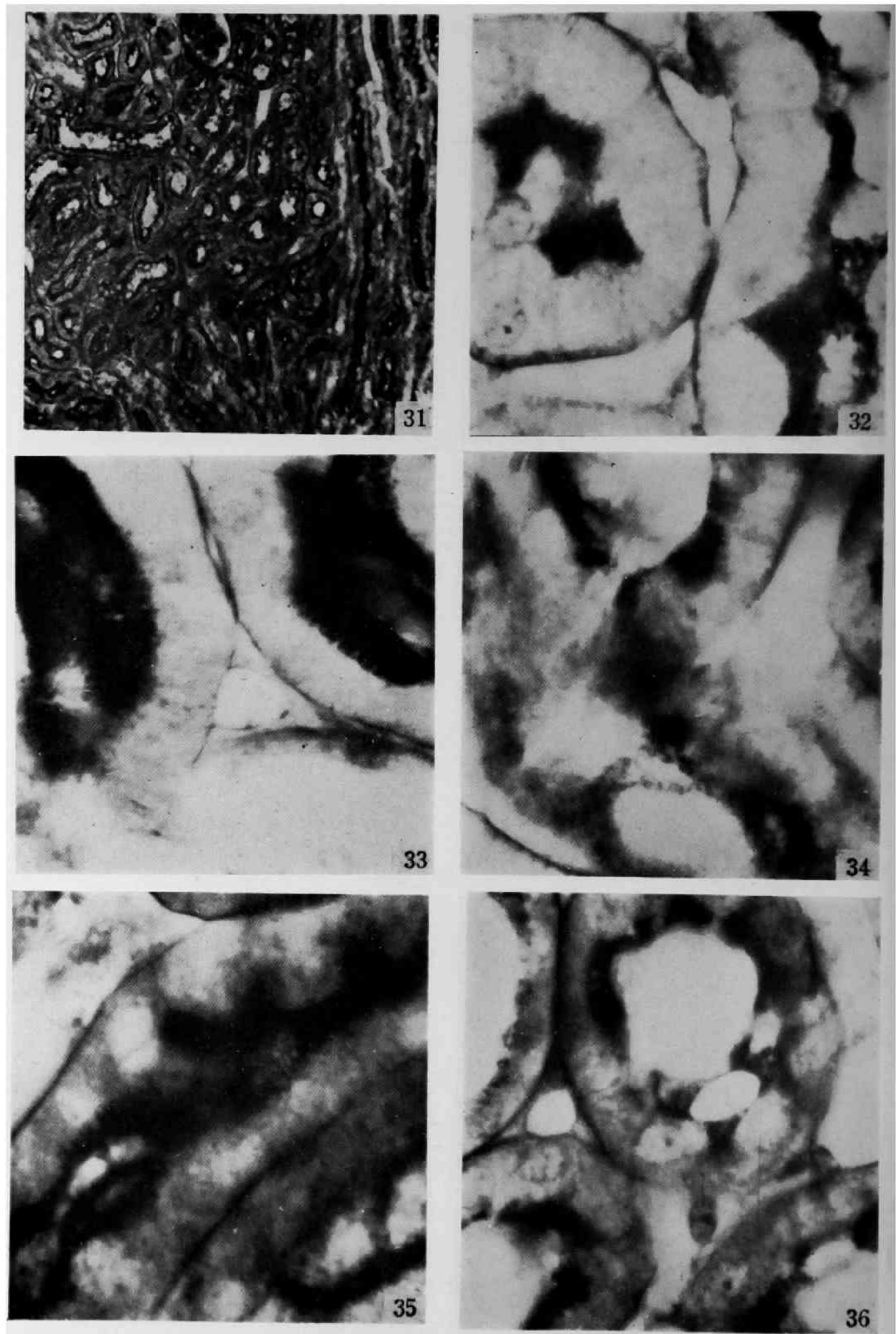
Plate VII
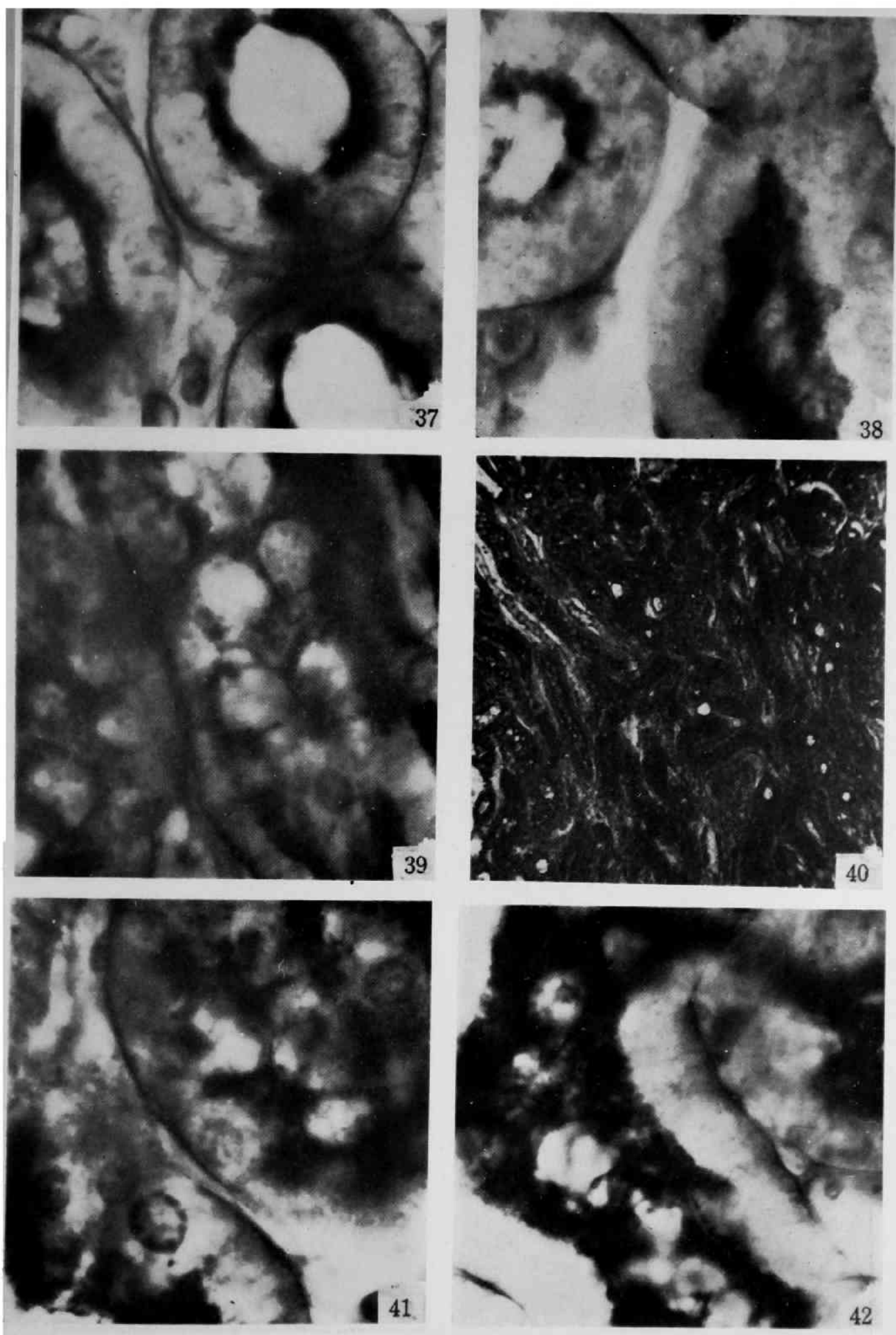

T. Kashimura 
Plate VII
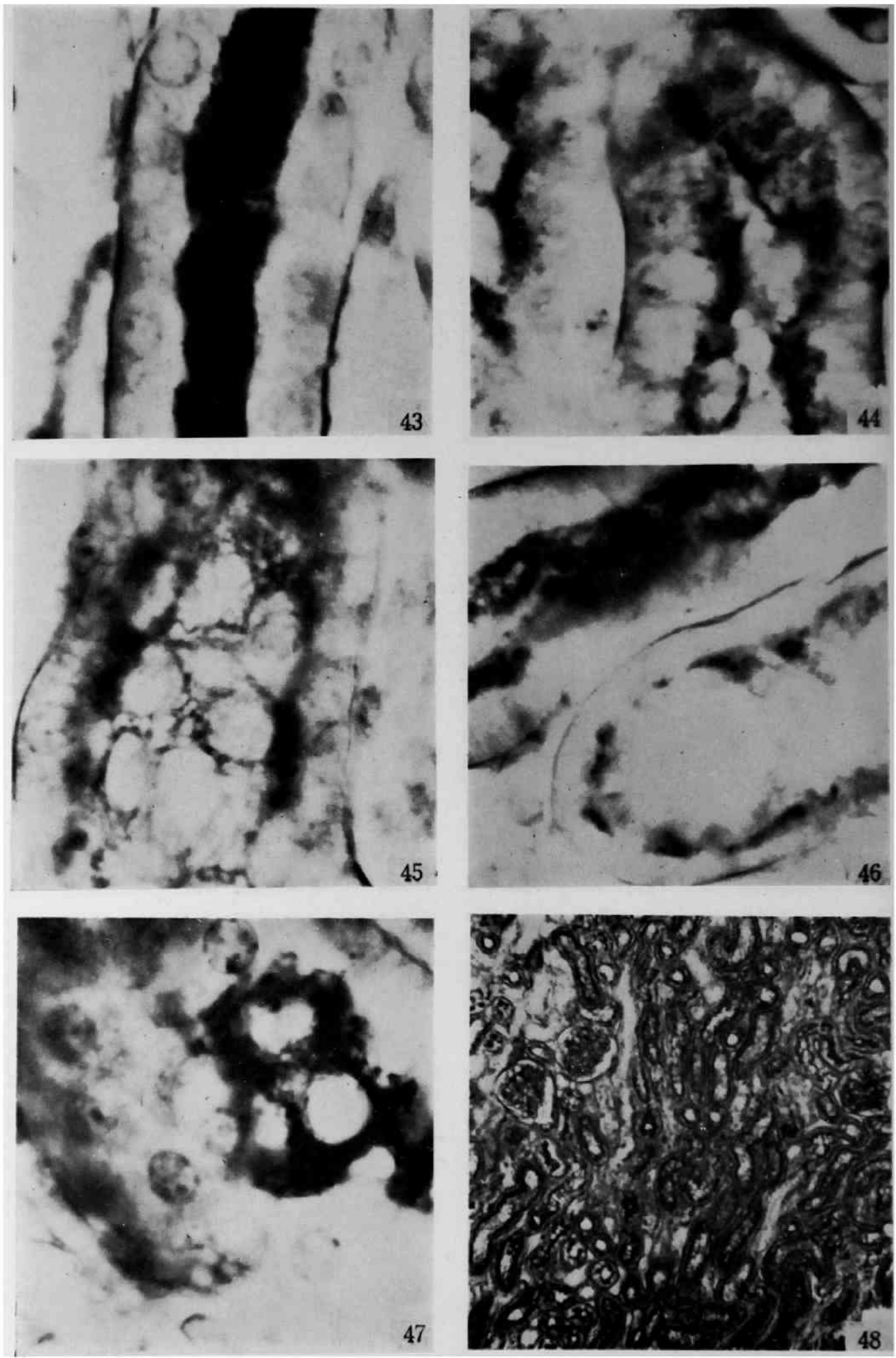

\section{T. Kashimura}


Plate IX
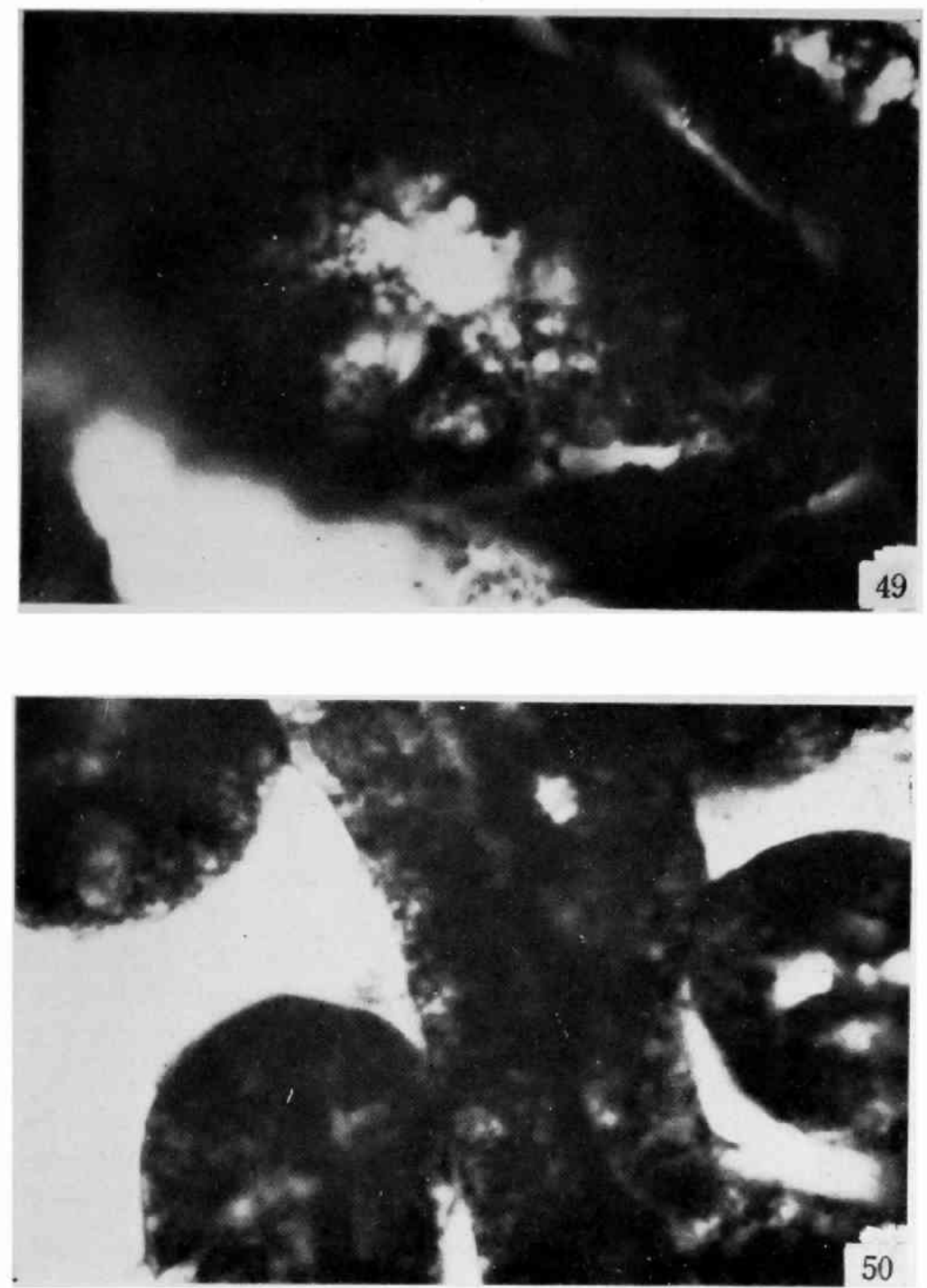

T. Kashimura 